Review began 08/05/2021 Review ended 09/19/2021 Published 09/24/2021

๑) Copyright 2021

Fatani et al. This is an open access article distributed under the terms of the Creative Commons Attribution License CC-BY 4.0. which permits unrestricted use, distribution, and reproduction in any medium, provided the original author and source are credited.

\section{Causes of the Failure of Biological Therapy at a Tertiary Center: A Cross-Sectional Retrospective Study}

Arwa Z. Fatani ${ }^{1}$, Nada A. Bugshan ${ }^{1}$, Hanan M. AlSayyad ${ }^{1}$, Mayar A. Shafei ${ }^{1}$, Nada M. Hariri ${ }^{1}$, Laila T. Alrashid ${ }^{1}$, Ahlam Y. Lasker ${ }^{1}$, Badreyah A. Aldauig ${ }^{1}$, Suzan M. Attar ${ }^{2}$

1. Faculty of Medicine, King Abdulaziz University, Jeddah, SAU 2. Department of Internal Medicine, King Abdulaziz University, Jeddah, SAU

Corresponding author: Arwa Z. Fatani, arwazuhairf@gmail.com

\section{Abstract}

\section{Introduction}

Rheumatoid arthritis (RA) is one of the most commonly encountered autoimmune diseases. Treatment generally includes disease-modifying anti-rheumatic drugs (DMARDs) and/or biological therapy. However, a significant proportion of the patients do not respond to treatment either as a (primary failure) or lose efficacy over time (secondary failure). Several factors are assumed to influence these conditions.

\section{Objectives}

To estimate the prevalence of failure of biological therapy in patients with RA and its causes.

\section{Methods}

A total of 335 RA patients who were diagnosed at a tertiary center in Jeddah, Saudi Arabia, and had a failure after receiving biological therapy were included in this study. Several variables were considered; patient's socio-demographic data, comorbid conditions, types of biological therapy, the duration of using biological therapy in months, number of biological therapies, allergic reactions, disease activity, and treatment duration.

\section{Results}

Overall the prevalence of failure to biological therapy was $58 \%$; $77 \%$ primary failure and $23 \%$ secondary failure. Patients with negative rheumatoid factor $(\mathrm{RF})(\mathrm{p}=0.006)$, using low-dose steroids, and with a longer disease duration had a significant failure of biological therapy $(\mathrm{p}=0.023)$.

\section{Conclusion}

A high percentage of RA patients had a failure of biological therapy. A multicentric trial is recommended to look for additional factors.

Categories: Internal Medicine, Rheumatology

Keywords: rheumatoid arthritis, biological therapy, refractory disease, failures, tnf inhibitors, rituximab

\section{Introduction}

The principal rheumatoid arthritis (RA) treatments are disease-modifying anti-rheumatic drugs (DMARDs) and/or biological DMARDs (bDMARDs) [1]. The introduction of bDMARDs designed to inhibit particular cellular or molecular targets specifically involved in the pathogenesis of the disease has significantly enhanced the outcome of RA therapy, resulting in clinical recovery or decreased activity of the disease. However, patients may also discontinue or delay care due to unfavored side effects. A randomized controlled trial in Greece showed that a considerable number of patients discontinued anti-tumor necrosis factor (TNF) therapy in 2019 either due to primary failure, secondary lack of response, or intolerance. Primary failure was observed in a considerable percentage of RA patients who don't respond to bDMARDs. Treatments that are possibly a result of non-TNF inflammatory pathways may be dominant in individual patients. In a previous study, it was found that starting DMARDs at a younger age, a high baseline disease activity score (DAS)-28 score, poorer early response within the first six months of treatment with bDMARDs (estimated by deltaDAS-28), and the presence of erosions were correlated with multi-refractoriness. However, anti-TNF agents are not effective in all patients. About $30 \%$ of patients treated with a TNF inhibitor failed to achieve an improvement of 20\% in American College of Rheumatology criteria (ACR20; primary failure or inefficacy), and more patients lose efficacy during therapy (secondary failure or acquired therapeutic resistance) or experience adverse events following treatment with a TNF inhibitor. In addition, others may demonstrate primary response initially and then develop over time (secondary failure) as a decline of efficacy. There is a 
previous study that documented the frequency of patients who do not achieve even the weakest response to the standard dosage of anti-TNF agents, which ranges between $28 \%$ and 58\%, namely, ACR20 (20\% improvement) response. Efficacy and adverse effects were the major factors for the discontinuation. The other factors are genetic mutations such as FAS-L and Caspase- 9 in the apoptosis-related genes. There are other contributing factors to secondary failure of bDMARDs, such as a longer period of illness lasting more than two years, smoking, and small bowel involvement [2]. An additional cause that influences TNF- $\alpha$ inhibitors' secondary failure is anti-drug antibodies development [3]. Methotrexate (MTX) discontinuation after the initiation of bDMARDs, adherence to treatment, or variations in the pharmacokinetics of TNF- $\alpha$ inhibitors. Still, there aren't enough studies in the literature. Therefore, we aimed to determine retrospectively the causes of bDMARDs failure in RA patients in a tertiary center.

\section{Materials And Methods}

A retrospective study was conducted from April 2015 to January 2019 at a tertiary center. The ethical committee approved this study. Our sample size comprised 335 patients (51 (11.9\%) of male patients) and (284 (66.2\%) of female) patients who had either primary or secondary failure to RA treatment. Primary failure is generally defined as no clinical response within the initial treatment while secondary failure is defined as loss of effectiveness of the drug after initial remission. The data included admitted patients and those in the database. Those who failed to respond to bDMARDs were not able to progress to a better prognosis and the desired treatment plan. While patients experiencing infection, pregnancy, or had recent cancer $<5$ years were excluded. The medical records were obtained, collected, and evaluated using a dedicated data extraction sheet along with examining the patient in the clinic. These records consisted of the patient's sociodemographic data based on their age, gender, nationality, body mass index (BMI), weight, height, smoking, disease duration, family history of RA, and a history of abortions and pregnancies. The comorbid conditions were diabetes mellitus, tuberculosis (TB), hypertension, liver cirrhosis, hyperlipidemia, cardiovascular diseases, cancer, lymphoma, chronic obstructive pulmonary disease (COPD), asthma. The medications were methotrexate, steroids, aspirin, non-steroidal anti-inflammatory drugs (NSAIDs), and traditional DMARDs. The use of bDMARDs included adalimumab, etanercept, infliximab, rituximab, and tocilizumab. The records also included the duration of using bDMARDs in months, the name of the first bDMARDs, the number of current bDMARDs, and the name of the second bDMARDs. Also, the study measured local and general allergic reactions and the lab results were rheumatoid factor (RF) positive or negative, RF level, anti-cyclic citrullinated peptide (CCP) level, erythrocyte sedimentation rate (ESR) level, c-reactive protein (CRP) level, and antinuclear antibodies (ANA) level. Disease activity was measured by the DAS-28 score and the result was measured as well. Data entry was done using Microsoft Excel 2016 (Microsoft Corporation, Redmond, WA) and statistical analysis was performed by using the Statistical Package for the Social Sciences (SPSS) software, version 21 (IBM Corp., Armonk, NY). Categorical variables, including primary variables, were described using frequencies. Continuous variables for normally distributed were described using means and standards. A univariate analysis was conducted for categorical variables using the chi-square test to check for all the possible causes. A test with a p-value of $<0.05$ was considered significant. All information in this study was confidential, with no access to data other than to those authorized.

\section{Results}

Twenty-six percent ( $26 \%$ ) of studied patients had an age ranging from ( 40 to $<50$ years), $84.8 \%$ were females with $2.5 \%$ who had a previous pregnancy and $7.4 \%$ who had a previous abortion. Of these patients, $65.1 \%$ were of Saudi nationality, $15.2 \%$ were current smokers, and $32.2 \%$ were obese. Most of the patients $(89.6 \%)$ were on monotherapy biological treatment, $19.1 \%$ had a family history of RA, and $43 \%$ had RF (Table 1). 


\section{Cureus}

\begin{tabular}{|c|c|c|}
\hline \multicolumn{2}{|l|}{ Variable } & No. (\%) \\
\hline \multirow{4}{*}{ Age } & $<40$ & $98(9.3)$ \\
\hline & $40-<50$ & $87(26)$ \\
\hline & $50-<60$ & $762(22.7)$ \\
\hline & $\geq 60$ & $74(22.1)$ \\
\hline \multirow{2}{*}{ Gender } & Male & $51(15.2)$ \\
\hline & Female & $284(84.8)$ \\
\hline \multirow{6}{*}{ For females } & Pregnancy & \\
\hline & Yes & $7(2.5)$ \\
\hline & No & $277(97.5)$ \\
\hline & Previous abortion & \\
\hline & Yes & $21(7.4)$ \\
\hline & No & $263(92.6)$ \\
\hline \multirow{2}{*}{ Nationality } & Saudi & $218(65.1)$ \\
\hline & Non- Saudi & $117(34.9)$ \\
\hline \multirow{3}{*}{ Smoking } & Yes & $51(15.2)$ \\
\hline & No & $274(81.8)$ \\
\hline & Ex-smoker & $10(3)$ \\
\hline \multirow{5}{*}{ BMI categories } & Underweight & $6(1.8)$ \\
\hline & Normal & $56(16.7)$ \\
\hline & Over & $74(22.1)$ \\
\hline & Obesity & $108(32.2)$ \\
\hline & Severe obesity & $91(27.2)$ \\
\hline \multirow{3}{*}{ Current biological therapy } & Monotherapy & $300(89.6)$ \\
\hline & Two types & $21(6.3)$ \\
\hline & Three types & $14(4.2)$ \\
\hline \multirow{2}{*}{ Family history of RA } & Yes & $64(19.1)$ \\
\hline & No & $271(80.9)$ \\
\hline \multirow{3}{*}{ RF } & Yes & $144(43)$ \\
\hline & No & $182(54.3)$ \\
\hline & Not applicable & $9(2.7)$ \\
\hline
\end{tabular}

TABLE 1: Distribution of studied patients according to their characters, smoking, BMI categories, currently used biological therapy, and a family history of RF

Ex-smoker; no longer smoking, RF; rheumatoid factor, RA; rheumatoid arthritis

Table 2 shows that $4.8 \%$ of patients had infertility, $12.2 \%$ had TB and most of it was of the pulmonary type (67.4\%). More than half of the patients (59.4\%) had comorbidities, where the most common was vasculitis (39.4\%), hypertension (HTN; 29\%), diabetes mellitus (DM; 28.1\%), and hyperlipidemia (23.9\%). 


\section{Cureus}

\begin{tabular}{|c|c|c|}
\hline \multicolumn{2}{|l|}{ Variable } & \multirow{2}{*}{$\begin{array}{l}\text { No. (\%) } \\
16(4.8)\end{array}$} \\
\hline & Yes & \\
\hline & No & $319(95.2)$ \\
\hline \multirow{2}{*}{ TB } & Yes & $41(12.2)$ \\
\hline & No & $294(87.8)$ \\
\hline \multirow{2}{*}{ Old TB } & Yes & $30(9)$ \\
\hline & No & $305(91)$ \\
\hline \multirow{2}{*}{ Latent TB } & Yes & $20(6)$ \\
\hline & No & $315(94)$ \\
\hline \multirow{4}{*}{ TB type } & Bone & $5(11.6)$ \\
\hline & Abdomen & $5(11.6)$ \\
\hline & Potts & $4(9.3)$ \\
\hline & Pulmonary & $29(67.4)$ \\
\hline \multirow{2}{*}{ Co-morbidity } & Yes & $199(59.4)$ \\
\hline & No & $136(40.6)$ \\
\hline \multirow{23}{*}{ Co-morbid disease } & DM & $94(28.1)$ \\
\hline & HTN & $97(29)$ \\
\hline & CVD & $31(9.3)$ \\
\hline & Hyperlipidemia & $80(23.9)$ \\
\hline & Hypoalbuminemia & $47(14)$ \\
\hline & Renal impairment & $46(13.7)$ \\
\hline & Previous lung diseases & $64(19.1)$ \\
\hline & Asthma & $29(8.7)$ \\
\hline & COPD & $18(5.4)$ \\
\hline & Lymphoma & $19(5.7)$ \\
\hline & Vasculitis & $132(39.4)$ \\
\hline & Osteoporosis & $40(11.9)$ \\
\hline & SLE & $41(12.2)$ \\
\hline & Psoriasis & $30(9)$ \\
\hline & Cirrhosis & $1(0.3)$ \\
\hline & Fatty liver & $58(17.3)$ \\
\hline & Cancer: & $34(10.1)$ \\
\hline & Cancer thyroid & $1(2.9)$ \\
\hline & Cancer lung & $13(38.2)$ \\
\hline & Multiplemyloma & $7(20.6)$ \\
\hline & Cancer breast & $4(11.8)$ \\
\hline & Cancer bladder & $4(11.8)$ \\
\hline & Cancer colon & $5(14.7)$ \\
\hline
\end{tabular}

TABLE 2: Distribution of studied patients according to the presence of infertility, TB, and 


\section{Cureus}

\section{comorbidities}

TB; tuberculosis, DM; diabetes mellitus, HTN; hypertension, CVD; cardiovascular diseases, COPD; chronic obstructive lung disease, SLE; systemic lupus erythematous

Table 3 demonstrated that $9.3 \%$ of patients had an allergic reaction to taken biological therapy and the most common allergic drug was rituximab (41.9\%). Of the patients, $49.6 \%$ had anti-CCP, $57.6 \%$ had anti-mutated citrullinated vimentin (MCV), 51.3\% had high ESR, 70.4\% had a CRP level >3, and 31.4\% had a doublestranded DNA (dsDNA) level of 0-200. Most of the patients (60\%) had a positive ANA, $83.6 \%$ had disease activity, and $48.7 \%$ had a DAS-28 of 3.2-5.1, 46.6\% had an aspartate aminotransferase (AST) of 10-40, 49\% had an alanine transaminase (ALT) of 7-56, and 19.4\% had an acetylsalicylic acid (ASA) of 65. Most of the patients were using NSAIDs (80.6\%), $56.7 \%$ were using a steroid dose of $<5 \mathrm{mg}, 80 \%$ were using Methtrx, and 78.5\% were using Methotrexate (MTX). The mean disease duration (months), HB, platelet, and creatine levels, and MTX dose were 38.91 \pm 70.16 months, $11.78 \pm 1.73$, 324.24 $\pm 100.71,88.65 \pm 389.67$, and 8.68 \pm 4.41 , respectively.

\begin{tabular}{|c|c|c|}
\hline \multicolumn{2}{|l|}{ Variable } & No. (\%) \\
\hline \multirow{2}{*}{ Allergic reaction to taken biological therapy } & Yes & $31(9.3)$ \\
\hline & No & $304(90.7)$ \\
\hline \multirow{5}{*}{ If yes, what is the allergic drug? } & Rituximab & $13(41.9)$ \\
\hline & Infliximab & $6(19.4)$ \\
\hline & Adalimumab (Humira) & $4(12.9)$ \\
\hline & Etanercept (Enbrel) & $4(12.9)$ \\
\hline & Tocilizumab & $4(12.9)$ \\
\hline \multirow{2}{*}{ Anti-CCP } & Yes & $166(49.6)$ \\
\hline & No & $169(50.4)$ \\
\hline \multirow{3}{*}{ Anti-MCV } & Yes & $193(57.6)$ \\
\hline & No & $141(42.1)$ \\
\hline & Not applicable & $1(0.3)$ \\
\hline \multirow{2}{*}{ ESR } & High & $172(51.3)$ \\
\hline & Normal & $163(48.7)$ \\
\hline \multirow{3}{*}{ CRP } & $>3$ & $236(70.4)$ \\
\hline & $\leq 3$ & $98(29.3)$ \\
\hline & Not applicable & $1(0.3)$ \\
\hline \multirow{4}{*}{ dsDNA } & $0-200$ & $41.5(31.4)$ \\
\hline & $201-300$ & $30.1(30.1)$ \\
\hline & $301-800$ & $26.9(26.9)$ \\
\hline & $>800$ & $1.5(1.5)$ \\
\hline \multirow{2}{*}{ ANA } & Positive & $201(60)$ \\
\hline & Negative & $134(40)$ \\
\hline \multirow{2}{*}{ Activity } & Yes & $280(83.6)$ \\
\hline & No & $55(16.4)$ \\
\hline \multirow{3}{*}{ DAS-28 } & $\leq 2.6$ & $2(0.6)$ \\
\hline & $2.6-3.2$ & $114(34)$ \\
\hline & 3.2-5.1 & 163 (48.7) \\
\hline
\end{tabular}




\section{Cureus}

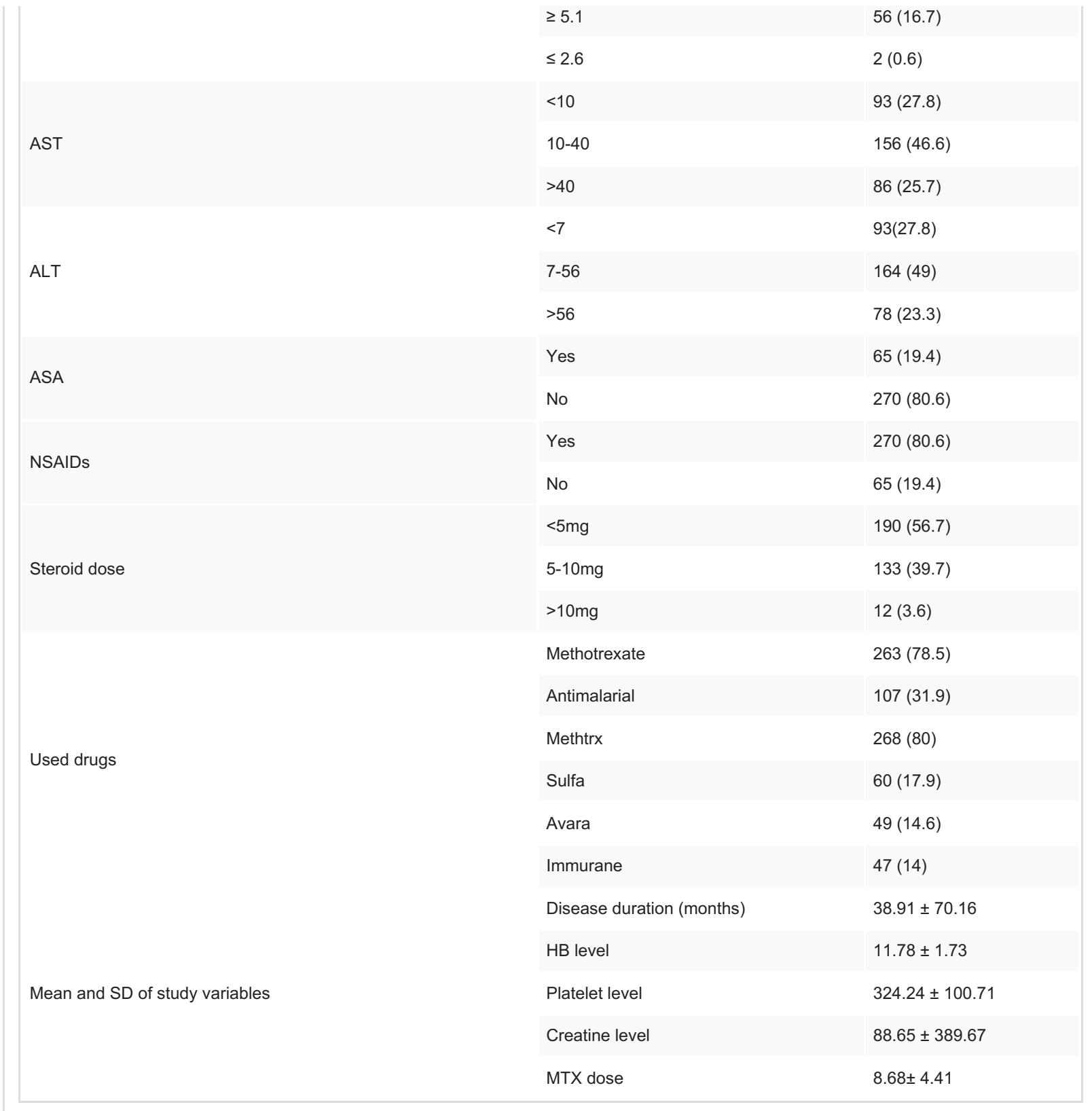

\section{TABLE 3: Distribution of studied patients according to the allergic reaction to taken biological}

therapy, clinical and laboratory data, and drugs used

Anti-CCP; anti-cyclic citrullinated peptide, Anti-MCV; anti-mutated citrullinated vimentin, ESR; erythrocyte sedimentation rate, CRP; C-reactive protein, dsDNA; double-stranded DNA, ANA; antinuclear antibodies, DAS-28; disease activity score, AST; aspartate aminotransferase, ALT; alanine transaminase, NSAIDs; nonsteroidal anti-inflammatory drugs, HB level; hemoglobin level, MTX dose; methotrexate dose, ASA; acetylsalicylic acid

Of the studied patients, $58.5 \%$ failed to respond to biological therapy. In contrast, only $41.5 \%$ responded to biological therapy.

Figure 1 shows that most of the patients were using Humira (34\%) and rituximab (49.3\%) as the first biological therapy and Humira (22.7\%) and rituximab (34\%) as the second biological therapy. 


\section{Cureus}

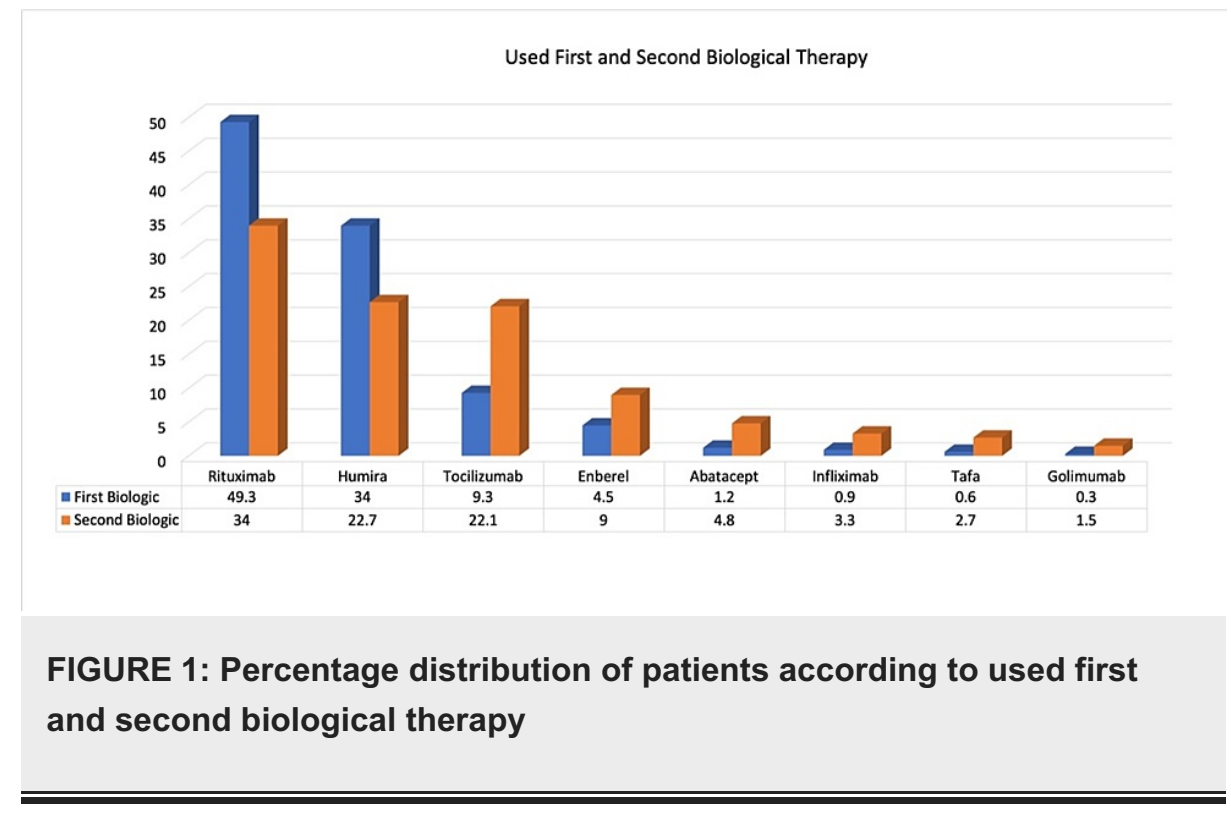

Table 4 shows that patients of Saudi nationality and those who did not have RF had a significantly higher percentage of those who had a failure of biological therapy $(\mathrm{p}=<0.05)$. On the other hand, a non-significant difference was found between failure of biological therapy and other patient characteristics such as smoking, BMI categories, and currently used biological therapy. 


\section{Cureus}

\begin{tabular}{|c|c|c|c|c|c|}
\hline \multirow{2}{*}{ Variable } & & \multicolumn{2}{|l|}{ Biological failure } & \multirow{2}{*}{$x^{2}$} & \multirow{2}{*}{ P-value } \\
\hline & & Present No. (\%) & Absent No. (\%) & & \\
\hline \multirow{4}{*}{ Age } & $<40$ & $37(37.8)$ & $61(62.2)$ & \multirow{4}{*}{1.75} & \multirow{4}{*}{0.627} \\
\hline & $40-<50$ & $41(47.1)$ & $46(52.9)$ & & \\
\hline & $50-<60$ & $31(40.8)$ & $45(59.2)$ & & \\
\hline & $\geq 60$ & $30(40.5)$ & $44(59.5)$ & & \\
\hline \multirow{2}{*}{ Gender } & Male & $22(43.1)$ & $29(56.9)$ & \multirow{2}{*}{0.06} & \multirow{2}{*}{10.796} \\
\hline & Female & $117(41.2)$ & $167(58.8)$ & & \\
\hline \multirow{2}{*}{ Nationality } & Saudi & $80(36.7)$ & $38(63.3)$ & \multirow{2}{*}{5.91} & \multirow{2}{*}{0.015} \\
\hline & Non- Saudi & $59(50.4)$ & $58(49.6)$ & & \\
\hline \multirow{3}{*}{ Smoking } & Yes & $25(49)$ & $26(51)$ & \multirow{3}{*}{3.08} & \multirow{3}{*}{0.214} \\
\hline & No & $108(39.4)$ & $166(60.6)$ & & \\
\hline & Ex-smoker & $6(60)$ & $4(40)$ & & \\
\hline \multirow{5}{*}{ BMI categories } & Underweight & $0(0.0)$ & $6(100)$ & \multirow{5}{*}{5.14} & \multirow{5}{*}{0.273} \\
\hline & Normal & $22(39.3)$ & $34(60.7)$ & & \\
\hline & Over & $29(3.2)$ & $45(60.8)$ & & \\
\hline & Obesity & $48(44.4)$ & $60(55.6)$ & & \\
\hline & Severe obesity & $40(44)$ & $51956)$ & & \\
\hline \multirow{2}{*}{ Family history of RA } & Yes & $32(50)$ & $32(50)$ & \multirow{2}{*}{2.35} & \multirow{2}{*}{0.125} \\
\hline & No & $107(39.5)$ & $164(60.5)$ & & \\
\hline \multirow{2}{*}{ RF } & Yes & $74(51.4)$ & 70 (48.6) & \multirow{2}{*}{10.18} & \multirow{2}{*}{0.001} \\
\hline & No & $65(34)$ & $126(66)$ & & \\
\hline
\end{tabular}

TABLE 4: Relation to failure of biological therapy and patients' characteristics, smoking, BMI categories, currently used biological therapy, and family history of RF

$\mathrm{RA}$; rheumatoid arthritis, RF; rheumatoid factor, BMI; body mass index

Table 5 shows that patients with vasculitis had a significantly higher percent of those who had a failure of biological therapy $(\mathrm{p}=<0.05)$. On the other hand, a non-significant difference was found between the failure of biological therapy and infertility, TB, and other comorbidities (cancer ( $\chi 2=1.3$, p-value $=0,254), \mathrm{COPD}$ $(\chi 2=1.55, p$-value $=0.213)$, asthma $(\chi 2=3.83$, $p$-value $=0.05)$, previous lung diseases $(\chi 2=0.47, p$-value $=0.47)$, renal impairment $(\chi 2=0.38$, p-value $=0.538)$, hypoalbuminemia $(\chi 2=0.63$, p-value $=0.424)$, hyperlipidemia $(\chi 2=0.22$, p-value $=0.639), \mathrm{CVD}(\chi 2=2.5, \mathrm{p}$-value $=0.113), \mathrm{DM}(\chi 2=0.54, \mathrm{p}$-value $=0.459)$, osteoporosis $(\chi 2=0.67$, $\mathrm{p}$-value $=0.411)$, SLE $(\chi 2=0.46, p$-value $=496)$, and psoriasis $(\chi 2=0.04, p$-value $=0.63))(p=>0.05)$. 


\section{Cureus}

\begin{tabular}{|c|c|c|c|c|c|}
\hline \multirow{2}{*}{ Variable } & & \multicolumn{2}{|l|}{ Biological failure } & \multirow{2}{*}{$x^{2}$} & \multirow{2}{*}{ P-Value } \\
\hline & & Absent No. (\%) & Present No. (\%) & & \\
\hline \multirow{2}{*}{ IB } & Yes & $23(56.1)$ & 18 (43.9) & \multirow{2}{*}{0.11} & \multirow{2}{*}{0.13} \\
\hline & No & 173 (58.8) & $121(41.2)$ & & \\
\hline \multirow{2}{*}{ Comorbidity } & Yes & $116(58.3)$ & $83(41.7)$ & \multirow{2}{*}{0.009} & \multirow{2}{*}{0.92} \\
\hline & No & $80(58.8)$ & $56(41.2)$ & & \\
\hline
\end{tabular}

TABLE 5: Relation to failure of biological therapy and presence of infertility, TB, and comorbidities

TB; tuberculosis

Table 6 shows that patients who had an allergic reaction to taken biological therapy, those who used NSAIDs and who had a steroid dose $<5 \mathrm{mg}$, who were not using antimalarial drugs, sulfa, or Immurane, and those with a longer disease duration had a significantly higher percentage of those who had a failure of biological therapy ( $\mathrm{p}=<0.05)$. On the other hand, a non-significant difference was found between the failure of biological therapy and other clinical and laboratory data and other drugs used (Methotrexate (DMARD) $(\chi 2=0.05, \mathrm{p}$-value $=0.813)$, Methtrx $(\mathrm{MTX})(\chi 2=0.37$, $\mathrm{p}$-value $=0.542)$, and Avara $(\chi 2=2.14, \mathrm{p}$-value $=0.143))$ $(\mathrm{p}=>0.05)$.

\begin{tabular}{|c|c|c|c|c|c|}
\hline \multirow{2}{*}{ Variable } & & \multicolumn{2}{|l|}{ P-value } & \multirow{2}{*}{$x^{2}$} & \multirow{2}{*}{ P-value } \\
\hline & & Absent No. (\%) & Present No. (\%) & & \\
\hline \multirow{2}{*}{ Allergic reaction to taken biological therapy } & Yes & $31(100)$ & $0(0.0)$ & \multirow{2}{*}{24.22} & \multirow{2}{*}{$<0.001$} \\
\hline & No & 165 (54.3) & $139(45.7)$ & & \\
\hline \multirow{2}{*}{ Anti-CCP } & Yes & $96(57.8)$ & $70(42.2)$ & \multirow{2}{*}{0.06} & \multirow{2}{*}{0.803} \\
\hline & No & $100(59.2)$ & $69(40.8)$ & & \\
\hline \multirow{3}{*}{ Anti-MCV } & Yes & $11(57.5)$ & $82(42.5)$ & \multirow{3}{*}{1.67} & \multirow{3}{*}{0.433} \\
\hline & No & $85(60.3)$ & $56(39.7)$ & & \\
\hline & Not applicable & $0(0.0)$ & $1(100)$ & & \\
\hline \multirow{2}{*}{ ESR } & High & $97(56.4)$ & $75(43.6)$ & \multirow{2}{*}{0.65} & \multirow{2}{*}{0.42} \\
\hline & Normal & $99(60.7)$ & $64(39.3)$ & & \\
\hline \multirow{3}{*}{ CRP } & $>3$ & $135(57.2)$ & $101(42.8)$ & \multirow{3}{*}{2.13} & \multirow{3}{*}{0.343} \\
\hline & $\leq 3$ & $61(82.2)$ & $37(37.8)$ & & \\
\hline & Not applicable & $0(0.0)$ & $1(100)$ & & \\
\hline \multirow{4}{*}{ dsDNA } & $0-200$ & 75 (45) & $64(46)$ & \multirow{4}{*}{2.1} & \multirow{4}{*}{0.53} \\
\hline & 201-300 & $61(60.4)$ & 40 (39.6) & & \\
\hline & $301-800$ & 57 (63.3) & 33 (36.7) & & \\
\hline & $>800$ & $3(60)$ & $2(40)$ & & \\
\hline \multirow{2}{*}{ ANA } & Positive & $114(56.7)$ & $87(43.3)$ & \multirow{2}{*}{0.66} & \multirow{2}{*}{0.415} \\
\hline & Negative & $82(61.2)$ & $52(88.8)$ & & \\
\hline \multirow{3}{*}{ Activity } & Yes & $164(58.6)$ & $116(41.4)$ & \multirow{3}{*}{0.003} & \multirow{3}{*}{0.957} \\
\hline & No & $32(58.2)$ & $23(41.8)$ & & \\
\hline & $\leq 2.6$ & $2(100)$ & $0(0.0)$ & & \\
\hline
\end{tabular}




\section{Cureus}

\begin{tabular}{|c|c|c|c|c|c|}
\hline \multirow{2}{*}{ DAS-28 } & $2.6-3.2$ & $70(61.4)$ & $441(38.6)$ & \multirow{2}{*}{5.35} & \multirow{2}{*}{0.148} \\
\hline & $3.2-5.1$ & $98(60.1)$ & 65 (39.9) & & \\
\hline \multirow{3}{*}{ NSAIDs } & $\geq 5.1$ & $26(46.4)$ & $30(53.6)$ & \multirow{3}{*}{9.56} & \multirow{3}{*}{0.002} \\
\hline & Yes & $169(62.6)$ & $101(37.4)$ & & \\
\hline & No & $27(41.5)$ & $38(58.5)$ & & \\
\hline \multirow{4}{*}{ Steroid dose } & $<5 \mathrm{mg}$ & $129(67.9)$ & $61(32.1)$ & \multirow{4}{*}{20.88} & \multirow{4}{*}{$<0.001$} \\
\hline & $5-10 \mathrm{mg}$ & $64(48.1)$ & $69(51.9)$ & & \\
\hline & $>10 \mathrm{mg}$ & $2(18.2)$ & $9(81.8)$ & & \\
\hline & Not applicable & $1(100)$ & $0(0.0)$ & & \\
\hline \multirow{5}{*}{ Quantitative variables } & Duration & $47.55 \pm 85.27$ & $26.55 \pm 36.48$ & $3.74^{*}$ & $<0.001$ \\
\hline & HB level & $11.73 \pm 1.72$ & $11.85 \pm 1.75$ & $0.85^{*}$ & 0.393 \\
\hline & Platelet level & $330.59 \pm 114.47$ & $315.29 \pm 76.7$ & $0.87^{*}$ & 0.38 \\
\hline & Creatine level & $96.93 \pm 50.8$ & $76.98 \pm 75.93$ & $1.04^{*}$ & 0.298 \\
\hline & MTX Dose & $8.58 \pm 4.58$ & $8.82 \pm 4.18$ & $0.81^{*}$ & 0.215 \\
\hline
\end{tabular}

TABLE 6: Relation of failure of biological therapy and allergic reaction to taken biological therapy, clinical and laboratory data, and drugs used

* Mann-Whitney test

Anti-CCP; Anti-cyclic citrullinated peptide, Anti-MCV; Anti-mutated citrullinated vimentin, ESR; erythrocyte sedimentation rate, CRP; C-reactive protein, dsDNA; double-stranded DNA, ANA; antinuclear antibodies, DAS-28; disease activity score, NSAIDs; nonsteroidal anti-inflammatory drugs, HB level;

hemoglobin level, MTX; methotrexate

By binary logistic regression analysis, using a steroid dose $<5 \mathrm{mg}$ was an independent predictor (risk factor) for the failure of biological therapy among studied patients $(\mathrm{p}=<0.05)$ as shown in Table 7.

\begin{tabular}{|l|l|l|}
\hline Variable & P-value & Odds ratio \\
\hline Nationality & 0.143 & 1.48 \\
\hline RF & 0.64 & 0.65 \\
\hline Vasculitis & 4.66 & 1.23 \\
\hline Allergic reaction to taken biological therapy & 0.998 & 5.04 \\
NSAID & 0.165 & 1.58 \\
\hline Steroid dose & 0.023 & 1.79 \\
Duration & 0.177 & 0.99 \\
\hline
\end{tabular}

\section{TABLE 7: Binary logistic regression analysis of risk factors of failure to biological therapy}

NSAIDs; nonsteroidal anti-inflammatory drugs, RF; rheumatoid factor

\section{Discussion}

This study estimated that more than half of RA patients had primary failure compared to secondary failure of biological therapy (bDMARD). More than half of the patients had comorbid conditions similar to previously conducted studies [4-6]. Patients who were RF negative had a significantly higher percentage of failure of biological therapy, contrary to a study that included 400 patients receiving bDMARD in the city of Bogotá, Colombia, which demonstrated that RF-negative patients have frequent remission and lower levels 
of disability compared to RF-positive patients treated with anti-TNF alpha agents [7]. Furthermore, an observational study was done between January 2000 and August 2019, which reported that the later that bDMARD was initiated and longer disease duration are prone to have multi-refractory diseases, as they present with advanced disease courses. Thus, early intervention with biological therapy is recommended in order to establish beneficial treatment outcomes [5]. Our data demonstrated that the higher the dose of steroids, the better the outcome, as most of our patients who received $>10 \mathrm{mg} / \mathrm{d}$ had less failure of biological therapy (18.2\%). Marije F. Bakker et al. showed that the inclusion of prednisone $10 \mathrm{mg} / \mathrm{d}$ from the start of an MTX-based, tight-control strategy slows erosive joint damage and further enhances clinical efficacy [8]. A non-significant relation was found between the failure of biological therapy and smoking compared to multiple studies that proved that smoking reduced the effect of both non-biological and biological DMARDs in RA treatment [7-9]. Most of our sample were females, as they are more likely to attain autoimmune disorders due to the hormonal changes women experience [10].

To date, no research has studied the prevalence of failure of biological therapy in the Middle East. Nevertheless, further work is valuable to identify the genetic and other constitutional factors, which may be linked to the disease activity that may determine the response of the failure to biological treatment, which is improbable to be a random effect. This study has several limitations, including the fact that it has a singlecenter, hospital-based, cross-sectional design. However, this is one of few studies that assessed the disease activity by accurate clinical measures using DAS-28. Larger, prospective, multi-centric cohort studies are needed to highlight the advocacy of applying DAS- 28 by physicians, consider failure as a complication in all RA patients, and be updated on the next step of management if so.

\section{Conclusions}

A high percentage of RA patients had a failure of bDMARDs. A multicentric trial is recommended to look for additional patient-related, drug, genetic, and environmental factors.

\section{Additional Information \\ Disclosures}

Human subjects: Consent was obtained or waived by all participants in this study. Animal subjects: All authors have confirmed that this study did not involve animal subjects or tissue. Conflicts of interest: In compliance with the ICMJE uniform disclosure form, all authors declare the following: Payment/services info: All authors have declared that no financial support was received from any organization for the submitted work. Financial relationships: All authors have declared that they have no financial relationships at present or within the previous three years with any organizations that might have an interest in the submitted work. Other relationships: All authors have declared that there are no other relationships or activities that could appear to have influenced the submitted work.

\section{References}

1. Strangfeld A, Hierse F, Rau R, et al.: Risk of incident or recurrent malignancies among patients with rheumatoid arthritis exposed to biologic therapy in the German biologics register RABBIT. Arthritis Res Ther. 2010, 12:R5. 10.1186/ar2904

2. Novella-Navarro M, Plasencia C, Tornero C, et al.: Clinical predictors of multiple failure to biological therapy in patients with rheumatoid arthritis. Arthritis Res Ther. 2020, 22:284. 10.1186/s13075-020-02354-1

3. Saevarsdottir S, Wallin H, Seddighzadeh M, et al.: Predictors of response to methotrexate in early DMARD naive rheumatoid arthritis: results from the initial open-label phase of the SWEFOT trial. Ann Rheum Dis. 2011, 70:469-75. 10.1136/ard.2010.139212

4. Marchesoni A, Zaccara E, Gorla R, et al.: TNF- $\alpha$ antagonist survival rate in a cohort of rheumatoid arthritis patients observed under conditions of standard clinical practice. Ann N Y Acad Sci. 2009, 1173:837-46. 10.1111/j.1749-6632.2009.04621.x

5. Soliman MM, Hyrich KL, Lunt M, Watson KD, Symmons DP, Ashcroft DM: Rituximab or a second anti-tumor necrosis factor therapy for rheumatoid arthritis patients who have failed their first anti-tumor necrosis factor therapy? Comparative analysis from the British Society for Rheumatology Biologics Register. Arthritis Care Res (Hoboken). 2012, 64:1108-15. 10.1002/acr.21663

6. Santos-Moreno P, Sánchez G, Castro C: Rheumatoid factor as predictor of response to treatment with antiTNF alpha drugs in patients with rheumatoid arthritis. Results of a cohort study. Medicine (Baltimore). 2019, 98:e14181. 10.1097/MD.0000000000014181

7. Bakker MF, Jacobs JW, Welsing PM, et al.: Low-dose prednisone inclusion in a methotrexate-based, tight control strategy for early rheumatoid arthritis: a randomized trial. Ann Intern Med. 2012, 156:329-39. 10.7326/0003-4819-156-5-201203060-00004

8. Rojas-Serrano J, Pérez LL, García CG, et al.: Current smoking status is associated to a non-ACR 50 response in early rheumatoid arthritis. A cohort study. Clin Rheumatol. 2011, 30:1589-93. 10.1007/s10067-011-17755

9. Saevarsdottir S, Wedrén S, Seddighzadeh M, et al.: Patients with early rheumatoid arthritis who smoke are less likely to respond to treatment with methotrexate and tumor necrosis factor inhibitors: observations from the Epidemiological Investigation of Rheumatoid Arthritis and the Swedish Rheumatology Register cohorts. Arthritis Rheum. 2011, 63:26-36. 10.1002/art.27758

10. Angum F, Khan T, Kaler J, Siddiqui L, Hussain A: The prevalence of autoimmune disorders in women: a narrative review. Cureus. 2020, 12:e8094. 10.7759/cureus.8094 